\title{
PERSPECTIVE
}

\section{The current state of limb salvage surgery}

\author{
Henry J. Mankin
}

Published online: 13 June 2009

(C) ISS 2009

The treatment of malignant tumors of the extremities has a long and sometimes distressing history. Resective surgery was clearly the goal of the tumor treatment teams, but the systems for reconstruction were so limited that the patients were sometimes severely disabled after wide resective surgery and amputation seemed to be the logical solution. In addition, the major difficulty encountered with treatment of tumors such as osteosarcoma, chondrosarcoma, Ewing's tumor, and some soft tissue malignant lesions was the possibility of a local recurrence after resective surgery, which appeared to greatly increase the risk of distant metastasis. In the early days, diagnosis was made by biopsy and unless the tumor was very small or quite benign on histological study, amputation seemed to be the logical protocol.

Several approaches were added in an attempt to salvage extremity function. Radiation alone was considered a possible method of therapy for some tumors, but when utilized without resective surgery often left the soft tissues and skin sufficiently damaged so as to require a later amputation. Furthermore, recurrence for radiation treated lesions was also a problem and treatment was almost always amputation. The early introduction of chemotherapy made a significant difference in the sense that it was now possible to treat the patient either after resective surgery or before and after and thus reduce the rate of local recurrence and also decrease the likelihood of metastasis. Indeed, the combination of radiation and chemotherapy and wide resective surgery greatly reduced the local recurrence rate and improved survival.

It seemed apparent then that some forms of reconstruction of bony parts could make amputations much less frequent and greatly improve the patient's functions. The reconstructive systems that were devised included metallic devices, autograft implants, and allograft transplants.

\footnotetext{
H. J. Mankin $(\bowtie)$

Orthopaedic Department,

Massachusetts General Hospital,

1122A Jackson Building,

Boston, MA 02114, USA

e-mail: hmankin@partners.org
}

Clearly, the most biologically acceptable of the three systems is autograft implantation. Osteogenetic bone substitutes have the ability to grow bone and to stimulate bone formation in the host tissues. The major type of such treatment is a fresh autograft from the iliac crest or from a rib or from the fibula or adjacent bone in the forearm or leg. If the tissue is transferred rapidly, the osteoblasts and osteocytes survive and can then begin to make new bone. Fibular grafts are easily inserted and survive and can rapidly replace the resected bone. In addition, the osteoadherin, hyaluronan, osteonectin, and bone sialoprotein present in the graft can influence the production and function of the osteoblasts to make new bone. One of the more common recent uses of such a technique is the implantation of a vascularized fibular component, which can not only add living bone, but can also bring in a vascular system that can aid the production of new bone at the site of prior injury or damage. The problems with fibular or iliac wing or rib grafts is that they are limited in size and shape and they also leave the patient with another site of disability in addition to the area of tumor resective surgery..

The second system is allografting, which has a long history. The National Naval Tissue Bank was established shortly after World War II and introduced the use of bone segments for treatment of local resective sites. Freezing the grafts reduced the host immune reactivity and allowed the inserted segment to remain intact and with limited local or systemic reactivity. The problem with the system was clearly that the bone grafts do not appear to be revascularized or heal rapidly at the host-donor junction sites. Furthermore, because they are not vascularized or develop a cellular system, they become "loci resistentia minoris" and are subject to non-union, fracture, joint arthritis and most problematical, infections. Although the grafts are now readily available from centers that have developed systems to reduce donor-transmitted infections, the rates of complications have discouraged many surgical teams. The use of some forms of bone morphogenetic proteins seems to help by causing an increased rate of synthesis of new osteoblasts or by activating existing osteoblasts.. Materials now available that are based on the presence of BMPs include 
Allomatrix (Wright), Dynagraft (GenSci), Intergro (Interpore), Osteofil (RTX), Opteform or Optefil (Exactech), Orthblast (GenSci), Dyndgraft (GenSci), Infuse (Medronic), DBX (Synthes), Grafton (Osteotech), and OP-1 (Stryker). It is important to note, however, that the use of these materials may represent some danger to the patient by increasing the likelihood of local or systemic tumor cell activity.

The third technique consists of metallic fixation devices. Initially, these were designed for each case and then constructed based on the observed mechanical structure, but this required a long period and was fraught with problems. In recent years the devices have been designed to include reconstructive systems for knee, hip and shoulder joints that are included in the resection. Another major contribution is the addition of modular systems for varying the length of the component. Of some concern is the evidence that these devices may loosen or result in fractures in the bone shaft after several years. In addition, it is difficult to attach muscular elements to these devices, such as those around the hip, shoulder or knee so that joint function may not be as good as normal or even as good as with allograft parts.

The final comment is what might one expect in the future. Radiation of the resected tumor containing bone and reimplantation has been considered possible for certain types of tumors and this may be successful, particularly if the patient receives chemotherapy or the tumor is relatively benign. The question of survival of the bone following radiation is perhaps an issue. It is also possible that local treatment of the tumor with implanted chemotherapy may decrease the likelihood of local recurrence, metastasis or bone failure [1-14].

\section{References}

1. Abjornson C, Lane JM. Demineralized bone matrix and synthetic bone graft substitutes. In: Friedlaender GE, Mankin HJ, Goldberg
VM, editors. Bone grafts and bone graft substitutes. Rosemont, IL: American Academy of Orthopedic Surgeons; 2006. p. 9-20.

2. Attawia M, Kadiyala S, Fitzgerald K, Kraus K, Bruder SP. Cell based approaches for bone graft substitutes. In: Laurencin CT, editor. Bone graft substitutes. West Conoshohocken, PA: ASTM International; 2003. p. 126-63.

3. Croteau S, Rauch F, Silvestri A, Handy RC. Bone morphogenetic proteins: from basic studies to clinical practice. Orthopedics. 1999;22:686-5.

4. Eckhardt J, Eilber FR, Doprey FJ, Mirra JM. The UCLA experience in limb salvage surgery for malignant tumors. Orthopaedics. 1985;8:612-21.

5. Eckhardt J, Eilber FR, Rosen G. Endoprosthetic replacement for Stage IIB osteosarcoma. Clin Orthop. 1991;270:202-13.

6. Einhorn TA. Clinical applications of recombinant human BMPs: early experience and future developments. J Bone Joint Surg. 2003;85 [Suppl 3]:82-8.

7. Friedlaender GE, Strong M, Tomford WW, Mankin HJ. Longterm followup of patients with osteochondral allografts: A correlation between immunologic responses and clinical outcome. Orthop Clin N Am. 1999;30:583-90.

8. Goldberg VM, Akhavan S. Biology of bone grafts. In: Friedlaender GE, Mankin HJ, Goldberg VM, editors. Bone grafts and bone graft substitutes. Rosemont, IL: American Academy of Orthopedic Surgeons; 2006. p. 1-8.

9. Hornicek FJ, Gebhardt MC, Sorger JI, Mankin HJ. Tumor reconstruction. Orthop Clin N Am. 1999;30:673-84.

10. Malawer MM, Chou LB. Prosthetic survival and clinical result with use of large-segment replacement in the treatment of high grade bone sarcoma. J Bone Joint Surg. 1995;77:1154-65.

11. Mankin HJ, Gebhardt MC, Jennings LC, Springfield DS, Tomford WW. Long term results of allograft replacement in the management of bone tumors. Clin Orthop. 1996;32:86-7.

12. Strong DM, Friedlaender GE, Tomford WW, et al. Immunological responses in human recipients of osseous and osteochondral allografts. Clin Orthop. 1996;326:107-14.

13. Wagner TD, Kobayashi W, Dean S, Goldberg SI, Kirsch DG, Suit $\mathrm{HD}$, et al. Combination short-course preoperative irradiation, surgical resection and reduced-field high-dose postoperative irradiation in the treatment of tumors involving the bone. Int $\mathrm{J}$ Rad Oncol Biol Phys. 2009;73:259-66.

14. Zeegen EN, Aponte-Tinao LA, Hornicek FJ, Gebhardt MC, Mankin HJ. Survivorship analysis of 141 modular metallic endoprostheses at early followup. Clin Orthop Relat Res. 2004;420:239-50. 